\title{
BEARING WITNESS TO THE CHALLENGE OF BREATHLESSNESS
}

LUCY SPEAKMAN, DAN BUtCHER AND SUE SCHUTZ

ABSTRACT Community Respiratory Nurse Specialists (CRNS) support patients at different stages of lung disease, witnessing the challenge of living with progressive illness for which there is no cure. Breathlessness is the most prominent and debilitating symptom experienced; it is frightening and distressing and very difficult to manage. Little is known about the experience of the CRNS role in witnessing the distress of patients specifically with breathlessness. The nurse may have cared for their patients over many months or years. This is important because in witnessing distress CRNSs engage in emotional labour, recognised to cause burnout and poor-quality care. This paper seeks to identify caring, bearing witness to suffering and vulnerability as components of emotional labour in the context of the CRNS role. It highlights the need for research to explore the experience of the CRNS role and insight into supporting people with long term breathlessness. It is more likely that well supported staff can provide sustained, supportive care to patients living with breathlessness. 


\title{
Bearing Witness to the challenges of Breathlessness
}

\author{
Abstract \\ Community Respiratory Nurse Specialists (CRNS) support patients at different stages of \\ lung disease, witnessing the challenge of living with progressive illness for which there is no \\ cure. Breathlessness is the most prominent and debilitating symptom experienced; it is \\ frightening and distressing and very difficult to manage. Little is known about the experience \\ of the CRNS role in witnessing the distress of patients specifically with breathlessness. The \\ nurse may have cared for their patients over many months or years. This is important \\ because in witnessing distress CRNSs engage in emotional labour, recognised to cause \\ burnout and poor-quality care. This paper seeks to identify caring, bearing witness to \\ suffering and vulnerability as components of emotional labour in the context of the CRNS \\ role. It highlights the need for research to explore the experience of the CRNS role and \\ insight into supporting people with long term breathlessness. It is more likely that well \\ supported staff can provide sustained, supportive care to patients living with \\ breathlessness.
}

\section{Key points}

- Breathlessness is a challenging and debilitating symptom for many people with respiratory conditions.

- Community Respiratory Nurses (CRNS) support patients with complex symptom management throughout what is often a very long disease process.

- Witnessing the suffering of patients due to breathlessness can cause distress to the nurse which may inadvertently influence the care given.

- Bearing witness to distress and vulnerability, caring and consequent emotional labour are essential components of good nursing care. 
- Research understanding the experiences of CRNS's supporting patients who are breathless has the potential to highlight the opportunities and barriers for nurses to deliver therapeutic care whilst witnessing distress.

- Progressing research regarding the role of the CRNS will add to the growing body of knowledge around supporting patients and their families with breathlessness.

\section{Reflective Questions}

- Do you always engage emotionally with patients and their families even when they are distressed?

- What is your experience of delivering "nursing care" when it is not "caring nursing"? How does this impact the patient and their family?

- How do you process the challenging experiences of bearing witness to distress?

- Do you have access to clinical supervision to support you and your team?

- Do you consider the impact of the emotional/psychological/existential components of the care you deliver, for you and the patients you care for?

\section{What am I adding to the body of knowledge?}

- There is little research published about the nurse's perspective of supporting patients with chronic breathlessness

- Highlighting the role of the CRNS in supporting patients with breathlessness will seek to explore its challenges, shedding new light on the demands on the nurse

- Understanding the impact on the nurse of bearing witness to distress when supporting patients with breathlessness may enable identification of opportunities and barriers to the delivery of therapeutic care

- This has the potential to enhance the delivery of compassionate care; offering emotional and psychological support enabling a patient-centred approach to care, integral in effective breathless management 


\section{Key Words}

Breathlessness, community respiratory nurse, bearing witness, caring, vulnerability, emotional labour

\section{Introduction}

This paper aims to consider the lived experience of the Community Respiratory Nurse Specialist (CRNS) supporting people with breathlessness in a context of emotional labour. This is a significant aspect of the CRNS role because to witness difficult breathing, something so life sustaining and fundamental to our survival as human beings, is to witness distress. When considering an affective symptom such as breathlessness, like pain, the experience of the symptom is directly influenced by the individual's thoughts and feelings as well as their physiology. Therefore, the importance of providing compassionate, therapeutic care is paramount to support individuals living with breathlessness. Better understanding of the components to delivering this care might give much needed insight into supporting breathless patients. By evaluating the components of emotional labour, the impact on the nurse will be discussed but also the consequence for the delivery of therapeutic nursing care. This will demonstrate that better understanding of this role might enable delivery of supportive care at a time for patients with breathlessness when compassionate, patient centred care is essential (Lovell et al. 2019).

Breathlessness is a common and distressing symptom in advanced disease affecting almost all people living with chronic obstructive pulmonary disease (COPD) and interstitial lung disease (ILD), and most people with chronic heart failure and advanced cancer (Solano, Gomes and Higginson 2006). The CRNS is well placed to support respiratory patients throughout the disease process with what are often very challenging, distressing symptoms, ultimately to the end of life. However, sustained witness to distress for nurses can cause burn out (Salyers et al. 2017), offers personal and professional challenge and impacts the 
delivery of holistic, therapeutic care (Sawbridge 2016). Emotional labour, a term

encompassing the emotional sacrifice nurses make of their personal thoughts and feelings to engage in therapeutic care with patients, is an under researched role requirement within nursing (Gray 2009). Seeking to understand the CRNS's experience of emotional labour in witnessing the distress of patients with breathlessness, will address this important aspect of therapeutic care. Whilst this paper specifically addresses the CRNS role; breathlessness and emotional distress, it can be considered an exemplar. The issues discussed will be relevant to all nurses working to achieve holistic care for patients with other intractable symptoms.

\section{What is the role of the Community Respiratory Nurse Specialist (CRNS) in supporting patients with breathlessness?}

The role of the CRNS is to maintain support to patients with respiratory disease, usually chronic obstructive pulmonary disease (COPD) and interstitial lung disease (ILD). Their support facilitates individuals to self-manage their disease and, where possible, remain in their own home. CRNS's help the patient to manage acute exacerbations, building supportive relationships to give practical guidance to both patients and wider family. Severe breathlessness is challenging to experience and can be very difficult to witness as Booth, Silvester and Todd (2003) and Hutchinson et al. (2018) have identified. Breathlessness is a poor prognostic indicator, and its unremitting nature can cause associated anxiety and depression for both patient and carer (Hutchinson et al. 2018). The CRNS often witnesses this increase of symptom burden manifesting in deteriorating breathlessness and a demise in self-confidence, of functional capacity and of quality of life. Long after medical care is optimised, the patient remains distressed living with refractory breathlessness. An experienced, skilled CRNS with advanced communication skills and an understanding of the complex components of breathlessness may well be the crucial team member supporting the patient throughout their disease trajectory to the end of life. 


\section{The CRNS's role as part of the wider team}

CRNS's work collaboratively with both Primary and Secondary care providers to support patients. Some teams have hospital in-reach to enable early discharge from hospital, they may work with Respiratory Consultants in clinics and the community to facilitate specialist care delivery. They will liaise with and advise GPs and Practice Nurses around maintenance treatment options and symptom management to complement their care of the patient, and at end of life, collaborate with district nurses and specialist palliative care nurses to advise on and deliver palliative and supportive care. They may support the delivery of Pulmonary Rehabilitation courses in delivering the courses or through education. They will be present for their patient throughout the illness which, with a condition such as COPD, can be many years.

\section{What are the implications for CRNSs of witnessing distress in their role and why is this important?}

Booth and Johnson (2019) identified the CRNS as the health care professional providing the most regular support and contact to patients who are breathless, and their families. This regular support enables nurses to witness the distress of breathlessness in assessment and symptom management, often building relationships that span months or years.

Supporting patients who have distressing and difficult to treat symptoms can impact the nurse, whether this is acutely or over a long period of time. Grace and Vanheuvelen (2019) identified that health care professionals who care for people with respiratory conditions suffer with high levels of psychological stress and burnout, more evident in higher status healthcare workers (physicians and nurse practitioners). Relative to other workers, nurses interact more frequently with patients and their families, responding to their needs and listening to their anxiety. However, understanding of why this should be particular to respiratory is not yet understood. This is something the European Respiratory Society (ERS) have identified as a priority for research to develop multidisciplinary respiratory care (Von 
Leupoldt et al. 2020). It is likely that high levels of psychological stress and burnout will be even more apparent in a post COVID-19 environment where all health care professionals including nurses will witness grief and loss both personally and professionally, acknowledged by Roberts et al. (2020) in respiratory care and (Graham 2020) more generally across the nursing workforce. Latimer et al. (2017) identify repeated exposure to the distress of others is associated with increased stress and burnout for nurses, often resulting in nurses leaving the profession. This distress was recognized by Salyers et al. (2017) in their systematic quantitative meta-analysis examining the relationship between burnout and quality of care. They analysed 82 studies up until 2015 and found a consistently negative relationship between provider burnout (emotional exhaustion, depersonalization and reduced personal accomplishment) and the quality (perceived quality and patient satisfaction) and safety of healthcare. Lower quality of clinical care included spending less time with patients and potentially putting them at risk of safety errors. This study's acknowledgement of the important connection between burnout and quality of care has implications for CRNSs.

The potential for burnout due to witnessing prolonged distress is an important factor when considering the CRNS role in supporting people with breathlessness. When exposed to the distress of others, there is likely to be a personal emotional cost to the CRNS which may then influence patient care as suggested by Salyers et al (2017). Coping with the distress of others requires "emotional labour": an aspect of caring recognised by (James 1989). However, engaging with, and witnessing the distress of others can also build trust and enable a closer relationship between the nurse and patient, ensuring the patient receives best supportive care (Gray 2009, Speakman 2018). It is therefore an important, yet challenging component in patient care that will impact the care delivered by the nurse and should be explored. 


\section{The challenges of witnessing distress for nurses: a philosophical exploration of caring, bearing witness and vulnerability}

Nurses make a unique contribution to patient care. The ubiquity of the term "Care" is both a strength and weakness, yet its meaning in nursing is quite variable. It applies not only in the practical sense (being with/helping), but in being psychologically and emotionally present (Eusaw and Chick 1999). Eriksson (1997) distinguishes between 3 perspectives: "caring nursing","nursing care" and "nursing nursing". Caring nursing is engaging with and caring for the patient without prejudice and focuses on need and suffering. Nursing care refers to specifically meeting the clinical needs of patients, care may be good "functional" care, but it does not necessarily constitute caring. Finally, "nursing nursing" refers to systematic planning of nursing care and can be administrative and technical. Reducing care in nursing in this way distinguishes aspects of the role within the process of care delivery. Sometimes the nurse will choose to engage and be present, sometimes to be efficient and functional. The challenges of an increasing scientific and technical approach to care can be a barrier to "caring nursing" but Eriksson (1997) suggests that the various obstacles that prevent nurses from seeing or providing care are in the human being (nurse) him/herself. Exploring and understanding the reasons for these obstacles might enable more "caring nursing" in practice.

Cody (2007) builds on the idea of caring nursing exploring the need for nurses to bear witness to patient's experiences of suffering. He suggests that to bear witness is to offer presence, with the nurse risking their own personal suffering. To bear witness is to attest personal authenticity of the nurse, a willingness to stay humble and uphold the person's truth, affirming the patient's dignity. Bearing witness to suffering is a moral choice nurses make when caring for patients, yet Cody suggests choosing not to bear witness and engage subjectively with the patient is an act of violation, refusing to acknowledge the unique experience of the patient. Bearing witness to suffering, a component of caring nursing, can 
be demonstrated through simple comfort measures, attentive listening, and small kindnesses as well as building to larger scale political and societal obligations.

Sellman (2005) and Carel (2009) explore the term vulnerability, to describe the lived experience of patients faced by disability and illness. The role of nurses to have "certain sorts of dispositions that are consistent with protection of... vulnerable people" (Sellman 2005, p8) demonstrates the call to emotional labour and imperative to mask any personal thoughts and feelings when with patients. Carel (2009) suggests that this vulnerability is a cost for the nurse in witnessing the vulnerability of others, routinely attempting to limit their vulnerability in witnessing pain and suffering. This puts the nurse in a unique position of vulnerability to the risks such intense situations involve.

\section{Emotional labour}

These discussions of caring, bearing witness to suffering and vulnerability, while integral components of holistic, compassionate care, enforce the need, rather than the choice of nurses engaging in emotional labour in the delivery of therapeutic care. Emotional labour was first described by Hochschild (2012) as displaying work appropriate emotions, which might sometimes be different from the emotions the individual may feel. Nurses work to reduce anxiety in the patient and display a sense of professionalism regardless of their own underlying emotions, often dealing with distress, tragedy, death and dying. This supports Smith's (2012) acknowledgement of emotional labour as a role requirement in nursing. Nurses are rarely conscious of emotional labour as an aspect of their work because it is bound up in gendered and professional status (Erikson and Grove 2008) and is an aspect rarely discussed (Sawbridge 2016). This idea that caring is "women's work" explains why skilled emotional management remains largely invisible, explored in depth by James (1989). The complexity of the care environment where there are staff shortages, sicker patients and pressured working environments can be barriers for all nurses to deliver caring nursing and engage emotionally. The cost of a loss of empathy and compassion was 
demonstrated in the Francis Report, examining the Mid-Staffordshire case in 2013. The focus of operational targets and financial balance over the provision of empathetic care demonstrated devastating costs to patients and their families. Kerasidou's (2019) study acknowledges empathy is often a cost when healthcare is driven by efficiency because it takes time and resources, enabling health care workers to be motivated and perform their duties. Emotional labour is an invisible feature of care and therefore rarely taken account of in management practice (Smith 2012). The impact of emotional labour, explored by Brighton et al. (2018) depend on the self-efficacy, expectations, personal knowledge and perceived support of the individual. These will determine the type of support that is required. This is echoed by McKinless (2020) who identified emotional resilience and emotional intelligence as key aspects of emotional labour in community nursing. She suggests coaching in these skills for nurses working in this service. While this may begin to address this integral aspect of care, it is the culture of the organisation enabling clinical supervision, manageable workloads, and recognition that within the demands of emotional labour "not having the expectation everyone is ok" (Brighton et al. 2019 p500).

\section{How does bearing witness to distress impact therapeutic care?}

The impact of emotional labour not only influences the wellbeing of the individual nurse, it is also an important element in compassionate care for patients (Smith 2012). Isabel Menzies's work in the 1960s identified a reductionist approach to nursing work, seen especially with an increasingly technical environment, with a task orientated focus unconsciously protecting the nurse from emotional labour, creating the antithesis of compassionate care, and coming at a cost to patients. Although care is now more patient centred and target-driven, disease-focused care is often prioritised over holistic, empathetic care (Kerasidou 2019). The role of the CRNS, focusing primarily on delivery of care to patients with respiratory disease prioritises knowledge and skills within the specialism. Knowledge is focused on disease management and prevention of disease (stopping smoking) as well as the specifics of oxygen therapy, non-invasive ventilation, and a range of 
inhaled therapies. Although these aspects of the role were recognised as priorities for research by respiratory nurses in a recent Delphi study (Kelly et al. 2018), advanced communication skills enabling empathy and reflective practice are just as relevant in this specialism if they are to deliver caring nursing and should be equally prioritised.

While it is clear emotional labour can cause burnout/distress/costs to the nurse, there is little known of its effects on therapeutic patient care. Gray (2009) recognised that engaging in emotional labour, the nurse helped patients "manage disclosures of a sensitive and emotional nature" ( $p 170)$ as well as increased information sharing opening democratic partnership working with patients and their families. Angel and Vatne (2017) consider the vulnerability experienced through illness and dependency on others but this vulnerability extends to the nurse in their engagement when caring for patients. Cody (2007) suggests that in bearing witness, the nurse can transcend suffering with the patient, finding a deeper meaning of the experience, moving beyond, and rising above with a sense of wholeness. This not only validating for the patient, it allows the nurse to "move beyond what is not yet" (p20). The experience of breathlessness inevitably results in feelings of vulnerability for patients due to the potential loss and threat for now and in the future (Angel and Vatne 2017). Breathlessness, like pain, is a "total" experience (Abernethy and Wheeler 2008), directly influenced by the individual's thoughts and feelings as well as bodily symptoms. The importance of providing compassionate, therapeutic care to support the individual through this experience is paramount. Better understanding of the components to delivering this care might give much needed insight into supporting breathless patients.

\section{Progressing research in breathlessness}

Living with COPD can become a way of life for patients and rather than consciously living with a disease, accepting a compromised quality of life and considerable suffering (Booth et al. 2003). Progress in Breathlessness research mirrors pain research (Addison 1984) considering the multiple factors that can contribute to its experience when it is a complex 
clinical syndrome (Johnson et al. 2017). In identifying the complexity of the components contributing to pain (fear, emotion, loss, spiritual and existential distress), research progressed in understanding the mechanisms and management for addressing pain, challenging the assumption that pain was considered an inevitable part of dying. Understanding of the different approaches needed to treat acute and chronic pain led to the benefits of holistic care being realised (Addison 1984). Now reducing or eliminating pain is considered a realistic goal at the end of life. In the same way breathlessness has been considered an inevitable part of living with and dying with respiratory disease (Oxley and McNaughton 2016). However, there is a growing understanding of the mechanics of breathlessness interventions that can reduce the symptom burden and improve quality of life, challenging this assumption (Currow et al. 2013, Faull et al. 2018). Much research around interventions to support patients with breathlessness and improve outcomes does not get delivered in clinical practice, other than by specialist Breathless intervention services. These services generally offer a model that combines respiratory and palliative care services taking a multiprofessional team approach. However, there are only a handful of such services across the UK and most patients will not have access to a Breathless Intervention Service (Booth and Johnson 2019). Currow et al. (2013) identify the need for a focus on future research to ensure evidence based non-pharmacological interventions are part of routine care. A supportive, therapeutic relationship established between nurse and patient as the burden of disease increases is greatly valued and can enable patients to manage their condition at home (Hutchinson et al. 2020).

While the role of the CRNS is important for patients, little is known about nurses' experience of caring long-term for patients with breathlessness. The experience of nurses in the more acute care of patients with breathlessness on ICU and at the very end of life in a Hospice are explored (Goodridge et al. 2012, Tarzian 2000) where distress is witnessed for intense, but for relatively short periods of time. These studies clearly demonstrate the challenge nurses experience when caring for patients who experience continuing breathlessness in the final 
stages of their life. They describe the challenge to stay present during suffering because it evokes such a strong embodied response, coming to terms with their own mortality, their taken for granted breathing and their own inevitable death. These descriptions suggest the cost of bearing witness to suffering which will surely be emulated in the long-term care of patients with breathlessness. Greater understanding of this experience will enable support and strengthening of the professional skills, acknowledging the demands of this role. To facilitate the delivery of effective breathlessness management that becomes integral to care for all respiratory patients, the experience of the nurse, pivotal in delivery of care and should be part of this research.

\section{Conclusion}

Breathlessness creates significant suffering for patients with cardiopulmonary disease (Currow et al. 2013). Addressing this symptom in the face of immense suffering for the patient, and distress for the carer (Johnson et al. 2014) can be challenging for nurses. This constitutes emotional labour, a role requirement and integral part of the culture of nursing care in the health service (Gray 2009). While emotional labour can be challenging for nurses (Smith 2012), it can inform interpersonal relationships and sustain the quality of nursepatient care. Recognising its explicit value rather than assuming it is a tacit aspect of the natural caregiving qualities of women enables greater understanding of this vital part of quality care within the NHS (Sawbridge 2017). In the role of the CRNS, the joy and burden of caring are witnessed. While the role is autonomous, varied, and important in providing continuity of care to respiratory patients and their families, the challenges within current times of staffing shortages and a global pandemic have highlighted nurses as human beings with a need to preserve their own wellbeing (Graham et al. 2020). Greater awareness and research of the emotional costs of bearing witness to suffering and distress, will limit detriment to the nurse personally. It will also enhance patient experience at a time when compassionate care is a vital component in addressing a challenging symptom like breathlessness. 


\section{References}

Abernethy, A. and Wheeler, J.(2008) Total dyspnoea Supportive and Palliative Care 2,2,110113

Addison, R. (1984) Chronic Pain Syndrome The American Journal of Medicine 3,1, 54-58 Angel, S. \& Vatne, S. (2017) Vulnerability in patients and nurses and the mutual vulnerability in the patient-nurse relationship. Journal of Clinical Nursing, 26, 1428-1437.

Booth, S. \& M. J. Johnson (2019) Improving the quality of life of people with advanced respiratory disease and severe breathlessness. Breathe, 15, 198-215.

Booth, S. M., S. B. S. C. M. S. C. Silvester \& C. B. A. M. A. P. A. Todd (2003) Breathlessness in cancer and chronic obstructive pulmonary disease: Using a qualitative approach to describe the experience of patients and carers. Palliative \& Supportive Care, 1, $337-44$.

Brighton, L. J., L. E. Selman, K. Bristowe, B. Edwards, J. Koffman \& C. J. Evans (2019) Emotional labour in palliative and end-of-life care communication: A qualitative study with generalist palliative care providers. Patient Education and Counseling, 102, 494-502 Carel, Havi.( 2009) A reply to 'Towards an understanding of nursing as a response to human vulnerability' by Derek Sellman: vulnerability and illness. 214-219. Nursing Philosophy

Cody, William. (2007) Bearing witness to suffering: participating in contranscendence. 17-21. International Journal for Human Caring.

Currow, D. C., I. J. Higginson \& M. J. Johnson (2013) Breathlessness - current and emerging mechanisms, measurement and management: A discussion from an European Association of Palliative Care workshop. Palliative Medicine, 27, 932-938. 
Eriksson, K. 1997. Understanding the world of the patient, the suffering human being: The new clinical paradigm from nursing to caring. 8-13. Advanced Practice Nursing Quarterly.

Erickson, R. J. \& W. J. C. Grove (2008) Emotional Labor and Health Care. Sociology Compass, 2, 704-733.

Euswas, P. and Chick, N.(1999) On caring and Being Cared for in: Madjar, I. \& J. A. Walton. 1999. Nursing and the experience of illness : phenomenology in practice. London ; Routledge.

Faull OK, Marlow L, Finnegan SL, and Pattinson, K. (2018) Chronic breathlessness: rethinking the symptom. Eur Respir J 51: 1702238 [https://doi.org/10.1183/13993003.022382017].

Grace, M. K. \& J. S. Vanheuvelen (2019) Occupational variation in burnout among medical staff: Evidence for the stress of higher status. Social Science \& Medicine, 232, 199-208.

Graham, Y. (2020). How a pandemic affects the mental health of the nursing workforce. ed. F. Ann, 20-22. Nursing Times (online).

Gray, B. (2009) The emotional labour of nursing - Defining and managing emotions in nursing work. Nurse Education Today, 29, 168-175.

Hochschild, A. R. 2012. The managed heart : commercialization of human feeling. University of California Press. http://site.ebrary.com/id/10555078 (last accessed http://search.ebscohost.com/login.aspx?direct=true\&scope=site\&db=nlebk\&db=nlabk\&AN=4 $\underline{50123}$ 
Hutchinson, A., N. Barclay-Klingle, K. Galvin \& M. J. Johnson (2018) Living with breathlessness: a systematic literature review and qualitative synthesis. European Respiratory Journal, 51, 1701477.

Hutchinson, A., K. Galvin \& M. J. Johnson (2020) "So, I try not to go ...” Acute-On-Chronic Breathlessness and Presentation to the Emergency Department: In-depth Interviews With Patients, Carers, and Clinicians. Journal of Pain and Symptom Management, 60, 316-325.

James, Nicky. 1989. Emotional labour: skill and work in the social regulation of feelings. 1542. The Sociological Review.

Johnson, M. J., J. Yorke, J. Hansen-Flaschen, R. Lansing, M. Ekström, T. Similowski \& D. C. Currow (2017) Towards an expert consensus to delineate a clinical syndrome of chronic breathlessness. European Respiratory Journal, 49, 1602277.

Kelly, C. A., A. J. Kirkcaldy, M. Pilkington, M. Hodson, L. Welch, J. Yorke \& K. Knighting (2018) Research priorities for respiratory nursing: a UK-wide Delphi study. ERJ Open Research, 4, 00003-2018.

Kerasidou, A. (2019) Empathy and Efficiency in Healthcare at Times of Austerity. Health Care Analysis, 27, 171-184.

Latimer, M., P. L. Jackson, F. Eugène, E. Macleod, T. Hatfield, E. Vachon-Presseau, P.-E. Michon \& K. M. Prkachin (2017) Empathy in paediatric intensive care nurses part 1: Behavioural and psychological correlates. Journal of Advanced Nursing, 73, 2676-2685. 
Lovell, N., S. N. Etkind, S. Bajwah, M. Maddocks \& I. J. Higginson (2019) Control and Context Are Central for People With Advanced Illness Experiencing Breathlessness: A Systematic Review and Thematic Synthesis. Journal of Pain and Symptom Management, 57, 140-155.e2.

McKinless, E. (2020) Impact of stress on nurses working in the district nursing service. British Journal of Community Nursing.

Oxley, R. \& J. Macnaughton (2016) Inspiring change. Current Opinion in Supportive and Palliative Care, 10, 256-261.

Roberts, N. J., K. Mcaloney-Kocaman, K. Lippiett, E. Ray, L. Welch \& C. Kelly (2020) Levels of resilience, anxiety and depression in nurses working in respiratory clinical areas during the COVID pandemic. Respiratory Medicine, 176, 106219.

Sawbridge, Y. and Hewison, A (eds) (2016) Compassion in Nursing: Theory, Evidence and Practice palgrave Macmillan: London

Salyers, M. P., K. A. Bonfils, L. Luther, R. L. Firmin, D. A. White, E. L. Adams \& A. L. Rollins (2017) The Relationship Between Professional Burnout and Quality and Safety in Healthcare: A Meta-Analysis. Journal of General Internal Medicine, 32, 475-482.

Sellman, D. (2005) Towards an understanding of nursing as a response to human vulnerability. Nursing Philosophy, 6, 2-10. 
Solano, J. P., B. Gomes \& I. J. Higginson (2006) A Comparison of Symptom Prevalence in Far Advanced Cancer, AIDS, Heart Disease, Chronic Obstructive Pulmonary Disease and Renal Disease. Journal of Pain and Symptom Management, 31, 58-69.

Speakman, L. (2018) Challenges of 'being with' patients nearing the end of life. 28-30. Nursing Times (online).

Smith, P. (2012) The Emotional Labour of Nursing Revisited: Can Nurses Still Care? 2nd Edition Palgrave Macmillan, London

Tarzian, A. J. (2000) Caring for Dying Patients Who Have Air Hunger. Journal of Nursing Scholarship, 32, 137-143.

Von Leupoldt, A., L. J. Brighton, J. Peters, E. Volpato, M. Verkleij, A. Hutchinson, M.Heijmans, I. Farver-Vestergaard, D. Langer \& M. A. Spruit (2020) ERS Scientific Working Group 09.04, "Psychologists and behavioural scientists": the next step towards multidisciplinary respiratory care. European Respiratory Journal, 56, 2001881. 